\title{
ESTUDO SENSORIAL E FÍSICO-QUÍMICO DE VEGETAIS ARMAZENADOS EM REFRIGERAÇÃO COM MONITORAMENTO DE PARÂMETROS
}

\author{
Isadora de Andrade Paulo* \\ Fernanda Raquel Wust Schmitz ${ }^{* *}$ \\ André Freitas ${ }^{* * *}$ \\ Sávio Leandro Bertoli ${ }^{* *}$ \\ Carolina Krebs de Souza
}

\begin{abstract}
RESUMO: 0 controle da temperatura e da umidade relativa em sistemas de refrigeração, para armazenamento de alimentos frescos, é fundamental para garantir boa aparência e manter as características físico-químicas, biológicas e sensoriais por períodos mais longos. Já que estes parâmetros afetam diretamente os atributos de qualidade nutricional, textura, aroma, sabor e aspecto visual. 0 objetivo deste trabalho foi avaliar 0 impacto da temperatura do sistema de refrigeração isotérmico $\left(3,3^{\circ} \mathrm{C}\right)$ e 0 monitoramento da umidade relativa na vida de prateleira dos vegetais (melancia, melão, aspargos, milho, ervilha, pimentão, aipo, pepino e alface romana). Foram realizadas análises da variação da massa, sensoriais e de cor com todos estes vegetais durante os 12 dias de armazenamento refrigerado. A análise sensorial foi realizada por um painel de sete julgadores treinados que avaliaram as amostras em uma escala hedônica não estruturada de nove pontos. De acordo com a avaliação sensorial, os alimentos foram rejeitados na seguinte ordem: ervilha torta no terceiro dia; milho no quarto dia; alface romana no quarto dia; pepino no sexto dia; aipo no oitavo dia; melancia no nono dia; melão no $11^{\circ}$ dia; aspargos no $11^{\circ}$ dia e pimentão verde no $12^{\circ}$ dia.
\end{abstract}

PALAVRAS-CHAVE: Armazenamento refrigerado; Vida de prateleira; Vegetais.

\section{SENSORIAL, PHYSICAL AND CHEMICAL ANALYSIS OF VEGETABLES AND FRUITS UNDER REFRIGERATION WITH MONITORING OF PARAMETERS}

\begin{abstract}
Control of temperature and relative humidity in refrigeration systems for storing fresh food is crucial to warrant its good aspects and maintain its physical, chemical, biological and sensorial characteristics for longer periods. In fact, these parameters directly affect nutritional quality, texture, aroma, taste and the fruit's visual aspects. Current research investigated the impact of temperature on the isothermal refrigeration system $\left(3.3^{\circ} \mathrm{C}\right)$ and the monitoring of Relative Humidity on shelf life of water melon, melon, asparagus, maize, beans, chili, celery, cucumber and lettuce. Mass variation, sensorial and color analyses with all the above-mentioned vegetables and fruits were performed during 12-day storage. Sensorial analysis was performed by seven judges who assessed samples by a nine-point non-structured hedonic scale. According to sensorial evaluation, food was refused as follows: beans on the $3^{\text {rd }}$ day; maize on the $4^{\text {th }}$ day, lettuce on the $4^{\text {th }}$ day, cucumber on the $6^{\text {th }}$ day, celery on the $8^{\text {th }}$ day, watermelon on the $9^{\text {th }}$ day, melon on $11^{\text {th }}$ day, asparagus on the $11^{\text {th }}$ day and chili on the $12^{\text {th }}$ day.
\end{abstract}

KEYWORDS: Refrigeration storage; Shelf Life; Vegetals.

\footnotetext{
Acadêmica de Engenharia de Alimentos na Universidade Regional de Blumenau, Brasil; E-mail: isadora.andradepaulo2@gmail.com

** Mestrado em Engenharia Química em andamento pela Fundação Universidade Regional de Blumenau

**** Engenheiro Químico

**** Doutor em Engenharia Mecânica pela Universidade Federal de Santa Catarina (UFSC); Docente do quadro da Fundação Universidade Regional de Blumenau (FURB), Brasil

* Doutorado internacional em Chemistry and Toxicology of Foods pela Universidade de Perúgia - Unipeg (Itália); Pós-doutorado em Engenharia Bioquímica na linha de pesquisa em Microbiologia Preditiva pela Universidade Federal de Santa Catarina (UFSC); Docente nos cursos de Engenharia de Alimentos, Engenharia Química e do Programa de Pós-graduação em Engenharia Química; Coordenadora do Curso de Engenharia de Alimentos na Universidade Regional de Blumenau (FURB), Brasil
} 


\section{INTRODUÇÃO}

A exigência do consumidor, quanto aos alimentos frescos, de boa aparência e com qualidade tem sido garantida pelo método de refrigeração (JACOBI; MACRAE; HETHERINGTON, 2000), que faz com que as características físico-químicas, biológicas e sensoriais se mantenham inalteradas por mais tempo.

Porém, fatores intrínsecos e extrínsecos têm grande influência na vida útil dos alimentos. Alguns deles são pH, acidez total, atividade de água, temperatura de armazenamento e umidade relativa (FOOD INGREDIENTS BRASIL, 2011). A temperatura pode ser considerada 0 principal fator externo na conservação dos vegetais, pois para cada aumento de $10^{\circ} \mathrm{C}$ na temperatura, a velocidade das reações biológicas aumenta de duas a três vezes, que pode resultar na deterioração do produto (FRIJA, 2012).

Para Chitarra; Chitarra (2005), o controle da temperatura é de suma importância, pois as alterações desta durante 0 armazenamento tem efeito direto nos atributos de qualidade como 0 valor nutricional, textura, aroma e sabor. Outro item a ser monitorado durante a refrigeração é a umidade relativa, pois valores inadequados podem causar murchamento, aumento da transpiração dos vegetais e, consequentemente, a perda de qualidade (GALVÃ0, 2009).

Variações de temperatura e umidade relativa no interior dos refrigeradores domésticos são comuns, sendo que a temperatura na gaveta do eletrodoméstico pode variar de $\pm 0,21^{\circ} \mathrm{C} \mathrm{a} \pm 3,60^{\circ} \mathrm{C}$ e a umidade relativa de $\pm 3 \% \mathrm{a} \pm 10,30 \%$, sendo que também há variações entre os diferentes modelos de refrigeradores (LUIZ, 2005).

Cada microrganismo possui um valor ótimo de pH para se desenvolver, porém a maioria do crescimento de microrganismos nos alimentos está associada próximo à neutralidade, $\mathrm{pH}$ entre 6,5 e 7,5 (SIDONIO, 2012).

Assim como as faixas de $\mathrm{pH}$ ideais para os microrganismos se desenvolverem, estes também necessitam de água disponível no alimento. Quanto menor a quantidade de água livre presente no alimento, menor é a possibilidade de multiplicação de microrganismos. Porte e Maia (2001) abordam que frutas e hortaliças possuem atividade de água maior ou em torno de $95 \%$, possibilitando o crescimento de microrganismos.

Este trabalho teve como objetivo estudar a influência do sistema de refrigeração isotérmico (temperatura média $3,3^{\circ} \mathrm{C}$ ) com controle $\mathrm{e}$ monitoramento da umidade relativa e eventuais flutuações destes parâmetros, na vida de prateleira dos vegetais (melancia, melão, aspargos, milho, ervilha, pimentão, aipo, pepino e alface romana) durante 12 dias de armazenamento.

\section{METODOLOGIA}

\subsection{MATÉRIA PRIMA}

Os alimentos analisados neste estudo foram adquiridos em uma rede de supermercado na região de Blumenau/SC. As amostras estudadas foram compradas no período da manhã no mesmo dia que os fornecedores entregaram os vegetais no supermercado (dia 0 do experimento), garantindo 0 frescor padronizado dos alimentos estudados.

Após a aquisição, os alimentos foram levados diretamente ao Laboratório de Análise Sensorial do Departamento de Engenharia Química, Campus II da FURB, onde se iniciou o preparo das amostras destes produtos para 0 início do estudo.

\subsection{PREPARO DAS AMOSTRAS E EXECUÇÃO DO EX- PERIMENTO}

Os alimentos foram manipulados com luvas apropriadas e todas as análises foram feitas em triplicata. Além da análise da variação da massa dos produtos, foram realizadas análises sensoriais $\mathrm{e}$ análise de cor das amostras alimentícias durante 0 armazenamento refrigerado $\left(3,3^{\circ} \mathrm{C}\right)$. As metodologias de cada análise são descritas abaixo e foram repetidas diariamente até 0 descarte da amostra. 
A melancia foi cortada ponta a ponta com faca de inox higienizada, de modo que totalizassem oito fatias. Porém para as análises, foi utilizada apenas uma fatia, a qual foi coberta com filme de policloreto de vinila (PVC).

Foram selecionados cerca de 80 gramas de ervilhas tortas frescas e estas foram acondicionadas em bandeja de alumínio sem proteção de PVC.

Tanto o melão quanto o pepino foram cortados ao meio, de ponta a ponta, com faca de inox higienizada e uma das metades foi coberta com filme PVC e utilizada nesta pesquisa.

Os talos de aipo e os aspargos foram cortados respeitando 0 tamanho da bandeja de alumínio (27 $\mathrm{x}$ $18,5 \times 5 \mathrm{~cm}$ ) aberta, onde foram acondicionados.

0 pimentão verde, as espigas de milho $e$ as cabeças de alface foram armazenados nas condições que chegaram ao laboratório, sem higienização, sem cortes e sem proteção por filme PVC.

Após o preparo dos alimentos, os mesmos foram submetidos à refrigeração em um sistema que permitiu o monitoramento de parâmetros de refrigeração (temperatura e umidade relativa) no cabinete, assim como a aquisição dos resultados de eventuais flutuações. No momento da abertura do refrigerador, para inserir ou retirar as amostras, ajustou-se um temporizador, em todos os dias de análise (12 dias) por 3 minutos. 0s alimentos foram armazenados, na primeira prateleira superior (melancia e melão), terceira prateleira (aspargos, milhos e aipo) e quinta prateleira (pimentão, ervilha e pepino) e a alface romana na segunda gaveta, localizada na parte inferior do refrigerador.

\subsection{ANÁLISES FÍSICO-QUÍMICAS}

Além do acompanhamento da variação da massa, foram realizadas análises de cor em triplicata de todos os produtos ao longo dos 12 dias ou até 0 momento de rejeição sensorial da amostra.

\subsubsection{Análise da Variação da Massa}

A variação da massa dos alimentos foi determinada de acordo com a metodologia de Agüero et al. (2011). Cada alimento foi pesado imediatamente após sua preparação e logo após ser retirado do refrigerador nos dias subsequentes, assim a variação da massa foi quantificada em relação à massa inicial de cada alimento e expressa em porcentagem.

Para análise da melancia foi utilizada balança digital Filizola BP 15 com capacidade de $15.000 \mathrm{~g}$. Os demais produtos foram pesados em balança de precisão ( \pm 0,0002), marca Gehaka modelo BG 1000.

0 filme de PVC utilizado para cobrir o pepino, o melão e a melancia foram mantidos durante as pesagens.

\subsubsection{Análise da Variação da Cor}

A variação de cor, ao longo dos dias de armazenamento refrigerado, foi avaliada de acordo com Kotsiras et al. (2016), porém, com 0 auxílio de um espectrofotômetro de esfera (modelo SP60 Series), fornecendo os valores diretos (sem conversão de dados) no sistema colorimétrico com precisão em termos numéricos. 0 espaço de cor utilizado foi $L{ }^{*} C$ ${ }^{*} \mathrm{H}$ *, em que $L$ * indica luminosidade, $C$ * representa saturação e $\mathrm{H}^{*}$ tonalidade. Este instrumento facilita a qualificação das cores e indica os valores para cada coordenada.

\subsection{ANÁLISE SENSORIAL}

A análise sensorial foi realizada para avaliar os atributos cor, homogeneidade, aspecto viçoso, áreas escuras, aroma e impressão global.

0 critério de aceitabilidade sensorial foi efetuado no Laboratório de Análise Sensorial da FURB, com um painel de sete julgadores treinados que avaliaram as amostras em cabines individuais sob iluminação branca. Os julgadores receberam uma ficha individual de avaliação com escala hedônica não estruturada de 9 pontos, sendo 9 a melhor nota para 0 critério avaliado e 1 a pior (INSTITUTO ADOLFO LUTZ, 2008). Esta pesquisa foi aprovada pelo Comitê 
de Ética da Universidade Regional de Blumenau (CAAE 48613415.1.0000.5370) sob o n. parecer 1330569.

\subsection{ANÁLISE ESTATÍSTICA}

Os resultados das análises físico-químicas e sensoriais foram submetidos à análise de desviopadrão utilizando-se 0 pacote de ferramentas de gráfico do software Excel, para Windows, versão 2016.

\section{RESULTADO}

\subsection{ANÁLISES FÍSICO-QUÍMICAS}

\subsubsection{Análises da Variação de Massa}

A Tabela 1 apresenta o percentual de perda de massa, e o respectivo dia em que as amostras foram descartadas no estudo sensorial realizado no Laboratório de Análises Sensoriais da Universidade Regional de Blumenau. 0 produto que apresentou maior velocidade de perda de massa foi a ervilha torta, enquanto 0 pimentão verde conservou esta característica por mais tempo, até atingir 0 peso específico para o descarte.

Observou-se que a ervilha torta apresentou redução de $12,79 \%$ da massa inicial já no quarto dia de armazenamento, sendo 0 primeiro produto a ser descartado. Em contrapartida, os aspargos mostraram-se mais resistentes, reduzindo $13,8 \%$ da massa inicial somente no $11^{\circ}$ dia de armazenamento. A melancia mostrou-se estável até o nono dia com perda de massa de 0,40\%, porém a partir deste dia observou-se exsudação e a perda de massa de 0,81\% no nono dia.

Tabela 1. Dia de descarte dos produtos vegetais e suas respectivas perda de massa $(\%$

\begin{tabular}{lcc}
\hline Produto & Perda de massa (\%) & Dia do descarte \\
\hline Ervilha & 12,79 & 3 \\
Milho & 5,03 & 4 \\
Alface Romana & 4,89 & 4 \\
Pepino & 1,20 & 6 \\
Aipo & 11,79 & 8 \\
Melancia & 0,81 & 9 \\
Melão & 2,67 & 11 \\
Aspargos & 13,80 & 11 \\
Pimentão Verde & 3,26 & 12 \\
\hline
\end{tabular}

0 Gráfico 1 apresenta a cinética da perda de massa de todos os alimentos durante 0 armazenamento refrigerado.

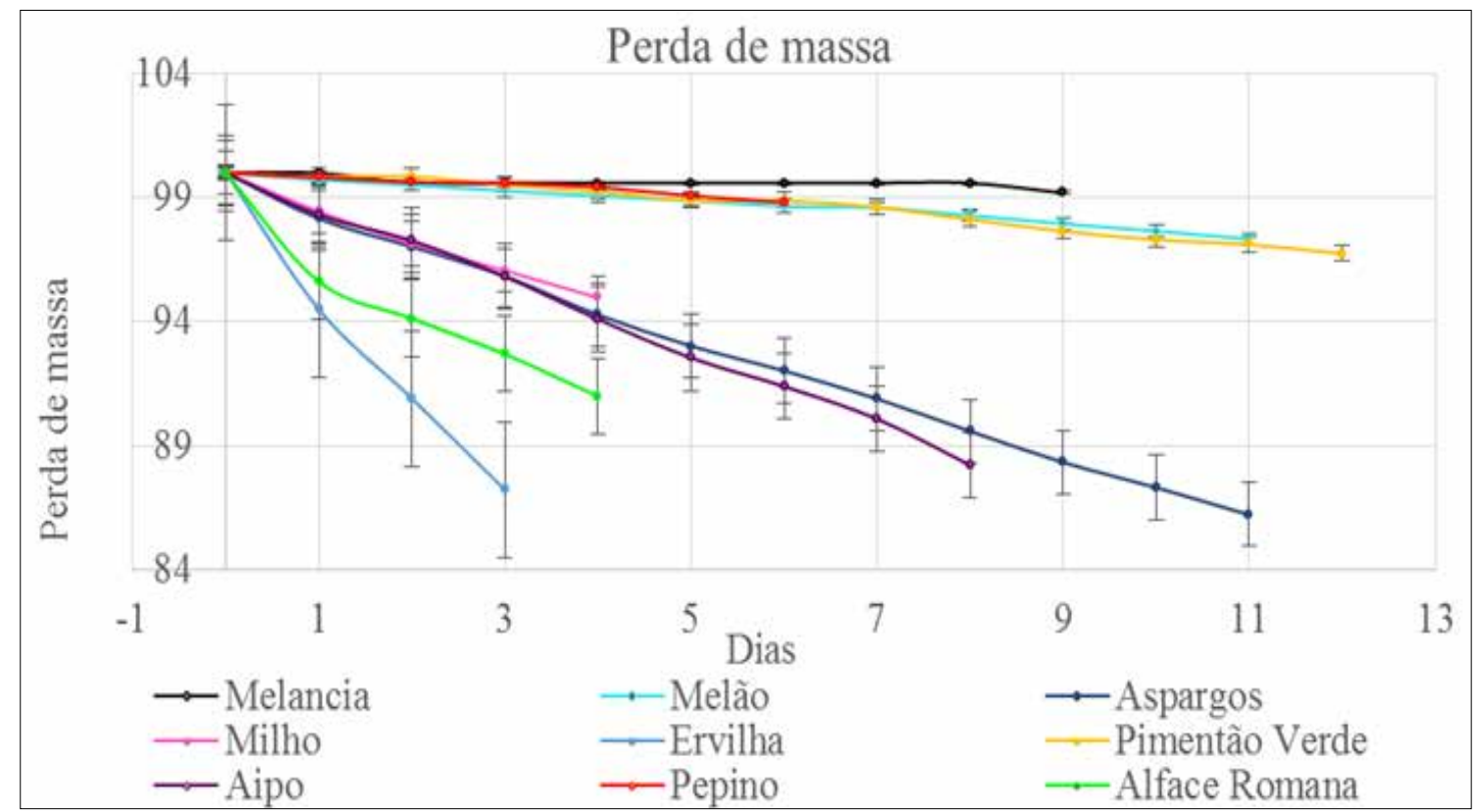

Gráfico 1. Cinética da perda de massa dos vegetais ao longo do armazenamento refrigerado (12 dias) 
A redução da massa dos vegetais estáassociada com a perda de umidade durante 0 armazenamento refrigerado, que ocorre pelos processos de respiração e transpiração dos vegetais (AGÜERO et al., 2011) e acarreta perdas nutricionais, alteração da textura, do aroma e murchamento (KOTSIRAS et al., 2016). Por estas alterações durante a vida de prateleira dos vegetais, a redução da temperatura e 0 aumento da umidade relativa no interior dos refrigeradores são realizados para minimizar a taxa de respiração e de transpiração e, consequentemente, minimizar a perda de massa e alterações sensoriais (GALVÃ0, 2009).

Por meio da cinética de variação da massa de cada alimento foi possível gerar a equação de regressão e o coeficiente de determinação $\left(R^{2}\right)$ que estão representados na Tabela 2, onde se verifica que a melancia não apresentou bom ajuste do modelo, provavelmente em virtude da imprecisão da balança utilizada.

Tabela 2. Equação de regressão e coeficiente de determinação das amostras

(continua))

\begin{tabular}{llc}
\hline \multicolumn{1}{c}{ Produto } & \multicolumn{1}{c}{ Equação } & $\mathbf{R}^{\mathbf{2}}$ \\
\hline Ervilha & $\mathrm{y}=-4,1966 \mathrm{x}+99,444$ & 0,9884 \\
Milho & $\mathrm{y}=-1,2445 \mathrm{x}+99,811$ & 0,9935 \\
Alface Romana & $\mathrm{y}=-2,095 \mathrm{x}+98,872$ & 0,9321 \\
\hline
\end{tabular}

(conclusão)

\begin{tabular}{llc}
\hline \multicolumn{1}{c}{ Produto } & \multicolumn{1}{c}{ Equação } & \multicolumn{1}{c}{$\mathbf{R}^{\mathbf{2}}$} \\
\hline Pepino & $\mathrm{y}=-1,884 \mathrm{x}+100,04$ & 0,9554 \\
Aipo & $\mathrm{y}=-1,4484 \mathrm{x}+99,982$ & 0,9979 \\
Melancia & $\mathrm{y}=-0,0613 \mathrm{x}+99,912$ & 0,6531 \\
Melão & $\mathrm{y}=-0,2287 \mathrm{x}+100$ & 0,9891 \\
Aspargos & $\mathrm{y}=-1,2333 \mathrm{x}+99,501$ & 0,9975 \\
Pimentão Verde & $\mathrm{y}=-0,2834 \mathrm{x}+100,3$ & 0,9743 \\
\hline
\end{tabular}

\subsubsection{Análise da Variação de Cor Utilizando Espectrofotômetro de Esfera}

Comparando o primeiro ao último dia de armazenamento de cada alimento, no quesito de alteração de cor (parâmetro luminosidade), o milho e a ervilha foram os alimentos que mostraram a menor variação.

Em contrapartida, a melancia, o melão e os aspargos obtiveram decréscimo de 9,18\%, 12,21\% e $21,95 \%$, respectivamente, em relação à luminosidade inicial. 0 pimentão verde também apresentou claramente um declínio dos valores de luminosidade no decorrer dos 20 dias de armazenamento $(54,97 \%)$. Estas mudanças estão apresentadas no Gráfico 2 com a representação da cinética durante 0 armazenamento.

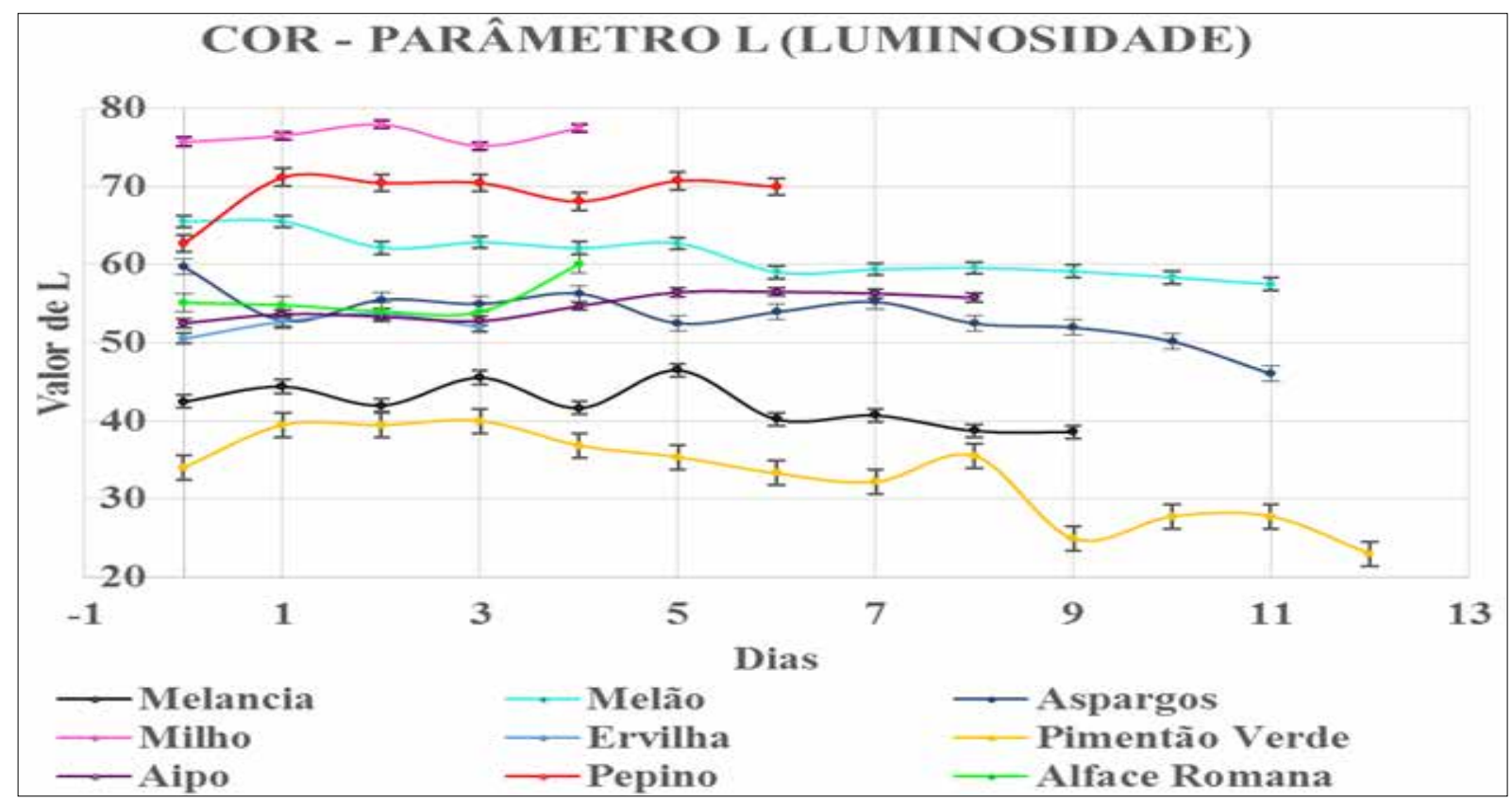

Gráfico 2. Variação da luminosidade das amostras ao longo dos dias de armazenamento 
As tonalidades (parâmetro $\mathrm{H}^{*}$ ) dos produtos apresentaram discretas variações conforme pode ser visto no Gráfico 3, que apresenta a cinética dos valores médios e seus respectivos desvios-padrão.

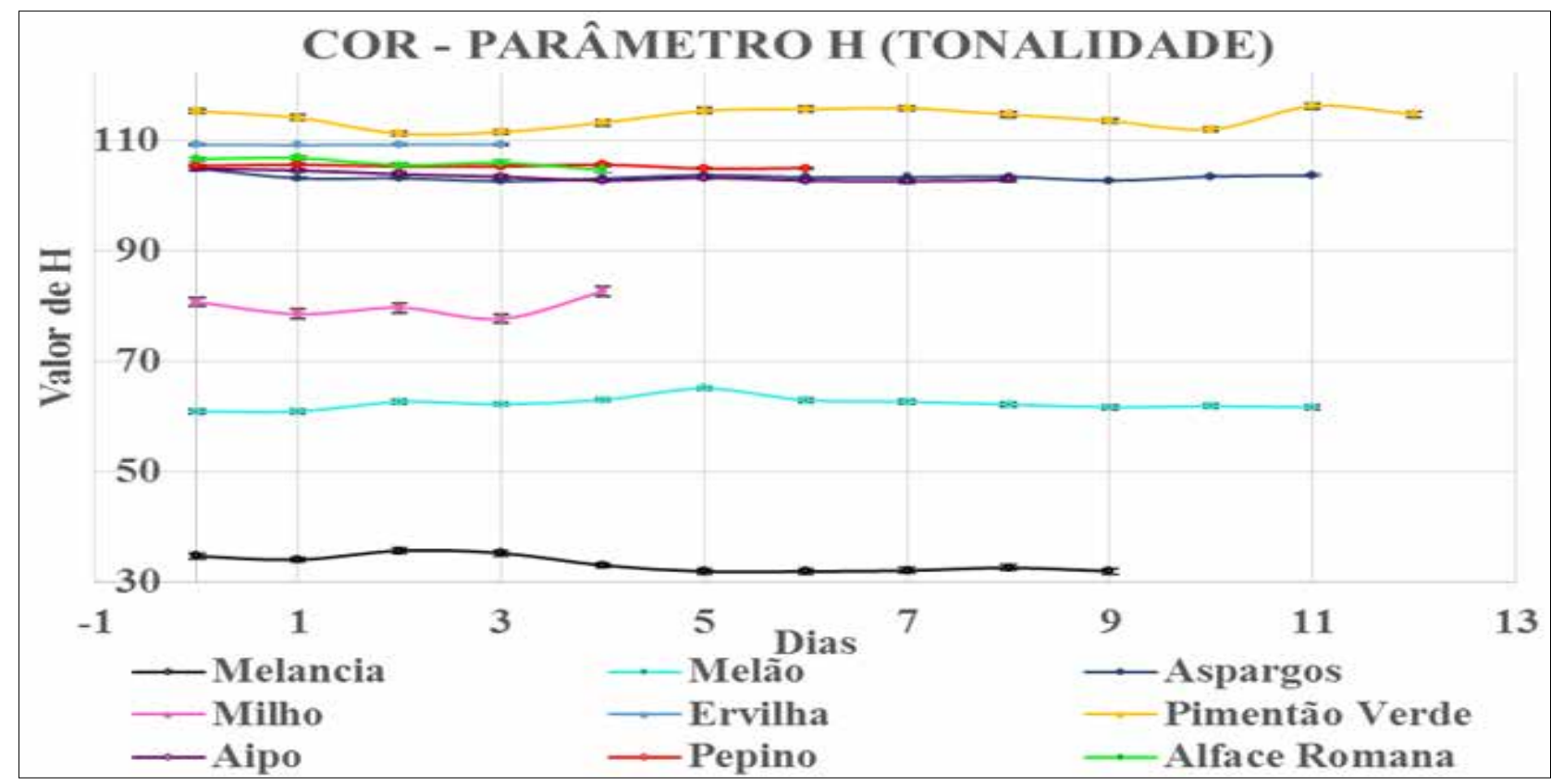

Gráfico 3 - Variação da tonalidade e ao longo dos dias de armazenamento refrigerado

As alterações nos parâmetros de cor sofridas por alguns dos vegetais podem ter ocorrido pelos danos mecânicos e também podem estar associados às reações de escurecimento não enzimático (MALHEIROS, 2007; MATTOS, 2008).

\subsection{ANÁLISE SENSORIAL}

Os gráficos, a seguir, apresentam as notas sensoriais das amostras durante 0 armazenamento até 0 momento da rejeição com relação aos atributos de cor, homogeneidade, viçosidade, áreas escuras, aroma e impressão global. A nota mínima para aceitação para 0 consumo por parte dos julgadores foi 6 . Abaixo deste índice a amostra foi descartada, do ponto de vista sensorial (impressão global).

As ervilhas tortas apresentaram estabilidade baixa e foi o primeiro vegetal a ser descartado nestas condições de armazenamento. Sensorialmente os atributos viçosidade e impressão global levaram à rejeição das ervilhas no segundo dia. No terceiro dia em relação à homogeneidade e os demais atributos (cor, áreas escuras e aroma) se manteve próximos a nota de rejeição sensorial como pode ser visualizado no Gráfico 5 . Além de a ervilha ser o primeiro alimento a ser rejeitado sensorialmente, foi o produto que perdeu massa com maior velocidade. Porém, de acordo com 0 estudo de Moraes (2006), a ervilha pode ser conservada de cinco a 15 dias quando armazenada à temperatura de $0^{\circ} \mathrm{C}$.

$\mathrm{Na}$ condição isotérmica de $3,3^{\circ} \mathrm{C}$, utilizada neste experimento, as espigas de milho apresentaram murchamento dos grãos já no segundo dia de armazenamento, sendo descartadas no quarto dia. 0 milho apresentou notas acima da rejeição sensorial (6) até 0 último dia, exceto para 0 atributo viçosidade que levaria à rejeição visual no quarto dia. Mamede et al.(2009) observaram em seus estudos que em uma temperatura maior, como de $11^{\circ} \mathrm{C}$, os resultados para a vida de prateleira do milho é de quatro dias e quando armazenado em temperaturas de $5^{\circ} \mathrm{C}$ a $8^{\circ} \mathrm{C}$ a vida de prateleira aumenta para seis dias. 


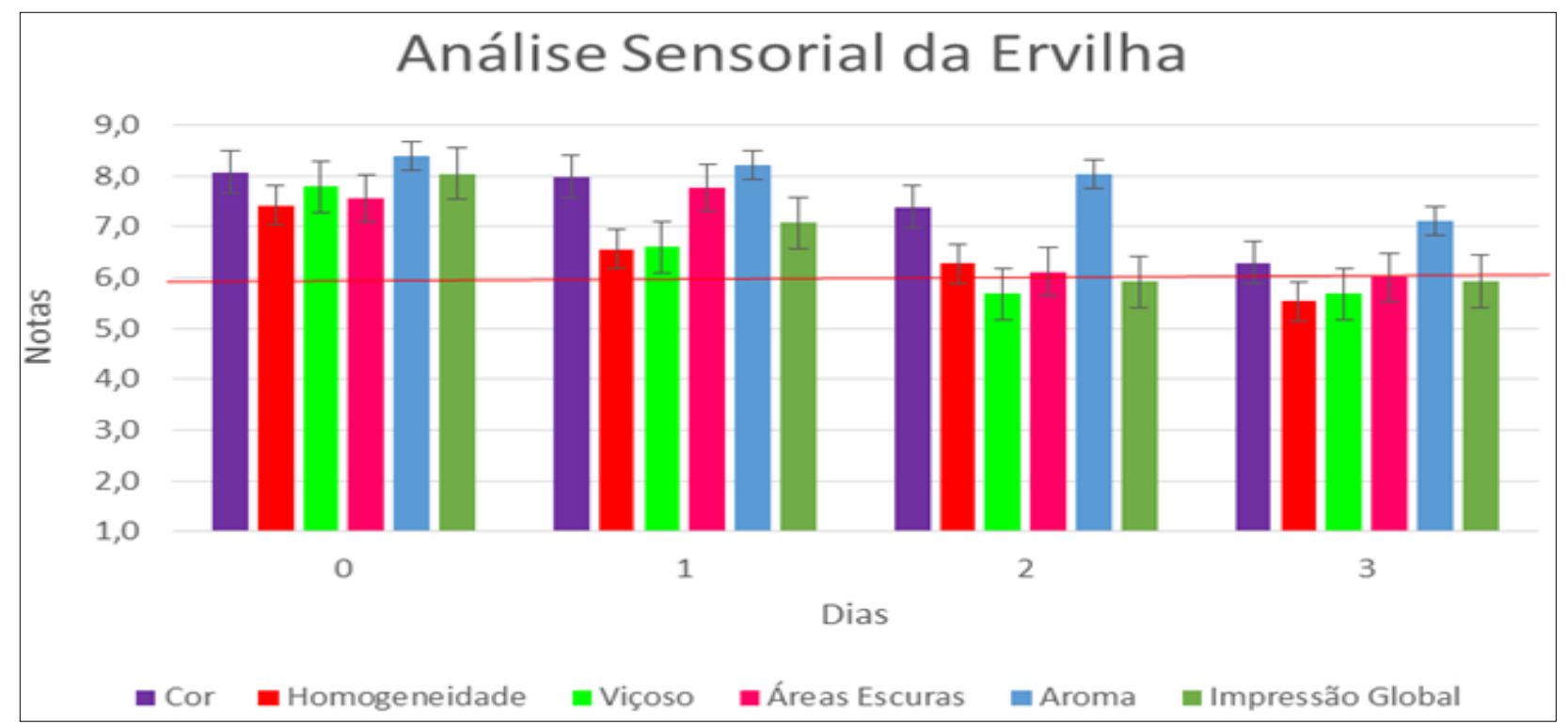

Gráfico 5. Avaliação sensorial das ervilhas durante os 4 dias de armazenamento refrigerado

As folhas de alface romana foram descartadas sensorialmente nos quesitos homogeneidade, viçosidade e áreas escuras no quarto dia e as demais (cor, aroma e impressão global) no quinto dia.

0 pepino assim como 0 aipo, também se manteve com suas características sensoriais visuais aceitáveis, sendo descartado no sexto dia. Segundo Moraes (2006), a temperatura recomendada para 0 armazenamento do pepino é de $10 \mathrm{a} 13^{\circ} \mathrm{C}$ para alcançar um período de dez a 15 dias de vida de prateleira. Os talos de aipo, apesar de exibir uma aparência atrativa no oitavo dia, foram descartados por atingir a variação máxima de perda de massa definida previamente (10\%) com base em estudos sensoriais realizados em pré-testes.

Observando os resultados da análise sensorial da melancia, em relaçãoàcor earoma, pode-se verificar que houve aceitação até 0 sexto dia. 0 s critérios de homogeneidade, impressão global e viçosidade foram aceitos até 0 quinto dia. Entretanto, as áreas escuras da melancia só se tornaram aparentemente inaceitáveis no nono dia, quando apresentou bolor e exsudação que levou ao descarte em virtude da rejeição de todos os atributos sensoriais.

Estas características apresentadas no dia do descarte são similares às observadas por Cartaxo; Sargent; Huber (1997), que retratam a perda de qualidade da melancia quando a mesma apresenta aspecto encharcado e escoamento do suco. Outros estudos como o de Fonseca; Rushing; Testin (2004) afirmam que a melancia passa a apresentar odores indesejáveis durante 0 armazenamento e Mao et al. (2006) identificaram crescimento microbiológico.

0 melão se manteve inalterado sensorialmente durante 0 armazenamento refrigerado, manifestando apenas alguns pontos de lesões por manipulação para a realização das análises, principalmente da cor com o contato direto do espectrofotômetro na superfície da fruta. Os resultados em relação ao melão indicaram alto índice de aceitabilidade pelos julgadores até 0 nono dia. A partir deste, o mesmo foi reprovado nos critérios de homogeneidade e viçosidade. Em relação à cor e à impressão global, os mesmos portariam ao descarte sensorialmente no décimo dia. Até 0 término do armazenamento refrigerado do melão ( $\left.11^{\circ} \mathrm{dia}\right), 0$ atributo aroma recebeu notas acima de 6 (considerando aceitável pelos julgadores).

0 estudo do comportamento do melão, em armazenamento refrigerado $5^{\circ} \mathrm{C}$, realizado por Durigan e Sargent (1999), demonstrou que as características 
sensoriais do melão se mantiveram por até sete dias. 0 que se aproxima dos resultados obtidos nesta pesquisa com armazenamento refrigerado de $3,3^{\circ} \mathrm{C}$.

Segundo Moraes (2006), os aspargos são conservados por 15 a 20 dias se armazenados em temperaturas entre 0 e $2^{\circ} \mathrm{C}$. Na temperatura de $3,3^{\circ} \mathrm{C}$, observou-se que a partir do segundo dia, as pontas dos aspargos começaram a escurecer juntamente com algumas áreas superficiais, tornando 0 produto não atrativo visualmente para 0 painel de julgadores. Para 0 aspecto viçosidade dos aspargos, segundo 0 painel de julgadores, houve rejeição do produto no quinto dia de armazenamento. Para áreas escuras e impressão global no sexto dia, homogeneidade no sétimo, cor oitavo e aroma no $11^{\circ}$. Mostrando que 0 aroma dos aspargos, ao longo do armazenamento refrigerado, nas condições estudadas, não alterou rapidamente como os demais atributos avaliados sensorialmente.

0 pimentão verde foi o produto que apresentou a maior estabilidade. Apenas no nono dia começou a apresentar leve murchamento em algumas áreas, que se intensificou a partir do $12^{\circ}$ dia. Este apresentou boa resistência aos efeitos dos parâmetros de refrigeração nos alimentos e foi descartado pelo critério de aspecto viçoso no décimo dia, impressão global no $11^{\circ} \mathrm{dia}$, homogeneidade e áreas escuras e cor no $12^{\circ}$ dia (Gráfico 6). 0 pimentão controle, estudado por Leme (2008), armazenado em temperatura de $10 \pm 1^{\circ} \mathrm{C}$ apresentou vida útil semelhante de 12 dias.

0 aparecimento de odores desagradáveis nos alimentos se deve ao aceleramento de reações químicas pela temperatura em que 0 alimento se encontra armazenado, pela presença de gases desfavoráveis ao vegetal, ao crescimento microbiano e à fermentação (TUDELA et al., 2013; DEROSSI et al., 2016).

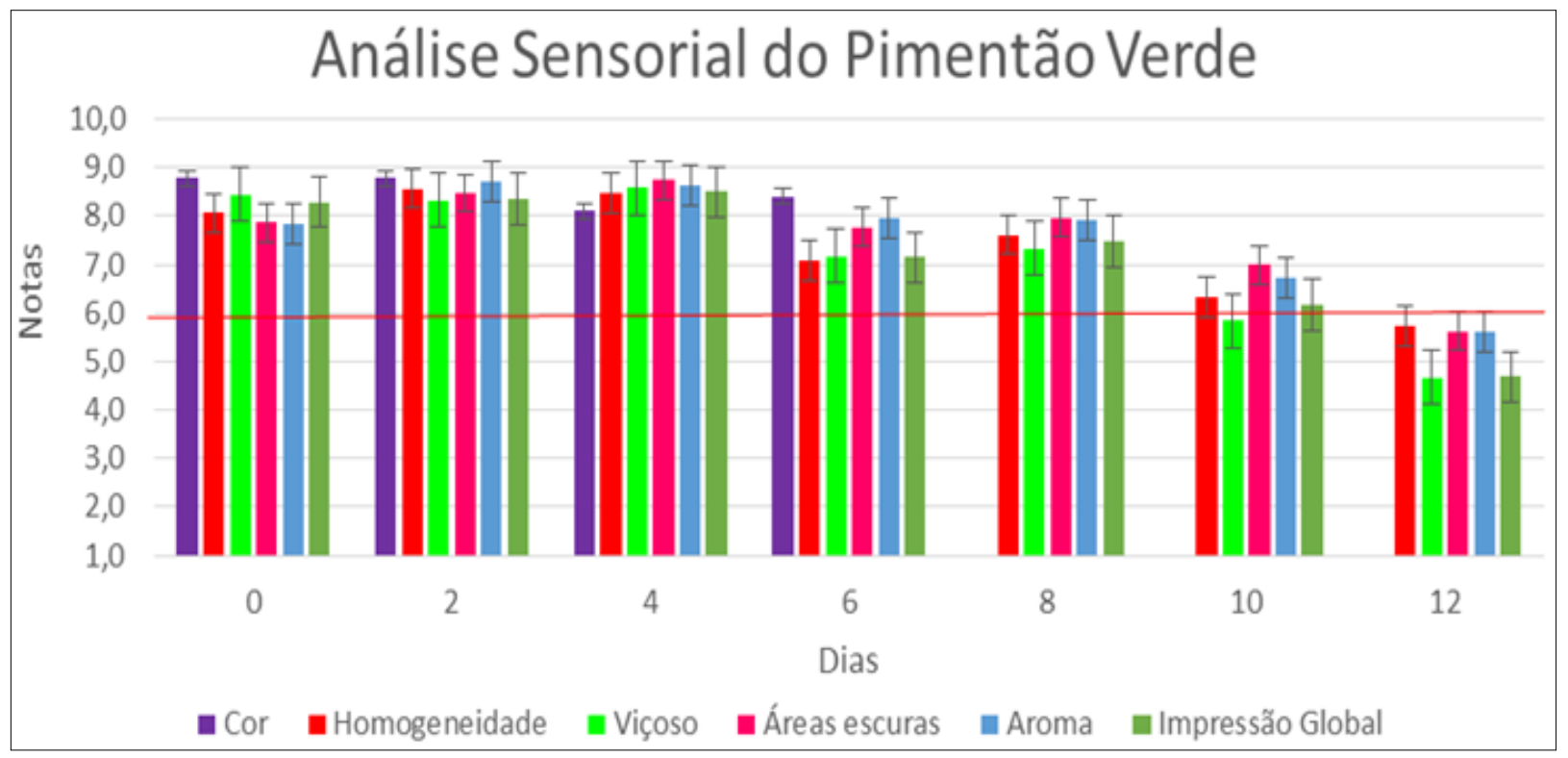

Gráfico 6. Avaliação sensorial do pimentão verde durante os 12 dias de armazenamento refrigerado 


\section{CONCLUSÃO}

Este estudo permitiu verificar que apesar das mesmas condições de armazenamento refrigerado, os alimentos estudados apresentaram distintos comportamentos.

Com base no painel de julgadores e considerando a impressão global das amostras 0 atributo que definiria a rejeição sensorial das mesmas, as quais seriam descartadas ou pouco atrativas para 0 consumo durante 0 período de armazenamento refrigerado, na seguinte ordem: ervilhas $\left(3^{\circ} \mathrm{dia}\right)$, alface romana ( $\left.4^{\circ} \mathrm{dia}\right)$, espigas de milho $\left(4^{\circ} \mathrm{dia}\right)$, pepino $\left(6^{\circ}\right.$ $\mathrm{dia})$, aipo ( $\left.8^{\circ} \mathrm{dia}\right)$, melancia $\left(9^{\circ} \mathrm{dia}\right)$, melão $\left(11^{\circ} \mathrm{dia}\right)$, aspargos $\left(11^{\circ} \mathrm{dia}\right)$ e pimentão verde $\left(12^{\circ} \mathrm{dia}\right)$.

Sendo assim, é possível verificar que cada alimento comporta-se de forma diferente quando armazenados sob as mesmas condições de temperatura e umidade relativa e que 0 descarte destes alimentos ocorre, principalmente, pela diminuição da massa, que é ocasionada pela perda de umidade dos alimentos, conferindo murchamento, perda do aspecto viçoso e da impressão global de cada vegetal estudado.

\section{AGRADECIMENTOS}

Agradecemos à FAPESC, por financiar esta pesquisa e à Universidade Regional de Blumenau, por disponibilizar sua infraestrutura de laboratórios.

\section{REFERÊNCIAS}

AGÜERO, M.V.; PONCE, A.G.; MOREIRA, M.R.; ROURA, S.I. Lettuce quality loss under conditions that favor the wilting phenomenon. Postharvest Biology and Technology, v. 59, p. 124-131, 2011.

CARTAXO, C.B.C.; SARGENT, S.A.; HUBER, D.J. Controlled atmosphere storage suppresses microbial growth on fresh-cut watermelon. Proceedings of Florida State Horticultural Society, Tampa, v.110, p.252-257,1997.
CHITARRA, M.I.F.; CHITARRA, A.B. Pós-colheita de frutas e legumes: fisiologia e manuseio. 2. ed. Lavras: UFLA, 2005. p. 785.

DEROSSI, A.; MASTRANDREA, M.L.; CHIARA, M.L.V., COLELLI, G. Application of multivariate accelerated test for the shelf life estimation of fresh-cut lettuce. Journal of Food Engineering, v. 169, p. 122-130, 2016.

DURIGAN, J.F.; SARGENT, E.A. Uso de melão cantaloupe na produção de produtos minimamente processados. Alimentos e Nutrição, São Paulo, v. 10, p. 69-77, 1999.

FONSECA, J.M.; RUSHING, J.W.; TESTIN, R.F. The anaerobic compensation point for fresh-cut watermelon and implications for postprocess handling. Postharvest Biology and Technology, v.39, p.562566, 2004.

FOOD INGREDIENTS BRASIL. Shelf life uma pequena introdução. Food Ingredients Brasil, n. 18, p 67-73. 2011.

FRIJA, S.N. Alterações nutricionais, organolépticas e de textura dos produtos hortícolas conservados: uma revisão. 2012. Dissertação (Mestrado) - Faculdade de Ciências e Tecnologia, 2012.

GALVÃO, H.L. Conservação pós-colheita de quiabo e jiló. 2009. 136f. Tese (Doutorado em Fitotecnologia) Universidade Federal de Viçosa, Viçosa, 2009.

INSTITUTO ADOLFO LUTZ - IAL. Métodos físicoquímicos para análise de alimentos. 4. ed. São Paulo: Instituto Adolfo Lutz, 2008. 1020 p.

JACOBI, K.K.; MACRAE, E.A.; HETHERINGTON, S.E. Efeitos do condicionamento de ar quente de frutas de manga 'Kensington' sobre a resposta ao tratamento de água quente. Postharvest Biology and Technology, v. 21, n. 1, p. 39-49, 2000.

KOTSIRAS, A.; VLACHODIMITROPOLOU, A.; GERAKARIS, A.; BAKAS, N.; DARRAS, A. I. Innovative harvast practices 
of Butterhead, Lollo rosso and Batavia green lettuce (Lactuca sativa L.) types grown in floating hydroponic system maintain the quality and improve storability. Scientia horticulturae, v. 201, p. 1-9, 2016.

LEME, S.C. Qualidade de pimentão armazenado sob refrigeração em atmosfera modificada. 2008. 71f. Dissertação (Mestrado) - Universidade Federal de Lavras, Minas Gerais, 2008.

LUIZ, K.M.B. Avaliação das características físicoquímicas e sensoriais dos tomates (Lycopersicum esculentun Mill) armazenados em refrigeradores domésticos. 2005. 107f. Dissertação (Mestrado) Universidade Federal de Santa Catarina, Florianópolis, 2005.

MALHEIROS, G.C. Estudo da alteração da cor e degradação da clorofila durante armazenagem de erva-mate tipo chimarrão. 2007. 104f. Dissertação (Mestrado em Ciência e Tecnologia de Alimentos) Universidade Federal de Santa Maria, 2007.

MAMEDE, A.M.G.N.; CHITARRA, A.B.; FONSECA, M.J.0.; SOARES, A.G.; FERREIRA, J.C.S.; LIMA, L.C.0. Conservação pós-colheita de espigas de milho verde minimamente processado sob diferentes temperaturas. Ciência e Agrotecnologia, Lavras, v. 33, n. 1, p. 200-206, jan./fev. 2009.

MAO, L.; JEONG, J.; QUE, F.; HUBER, D. J. Physiological properties of fresh-cut watermelon (Citrillus lanatus) in response to 1-methylcyclopropene and postprocessing calcium application. Journal Science Food Agricultural, v.86, p.46-53, 2006.

MATTOS, L. M; MORETTI, C. L; CHITARRA, A. B; CHITARRA, M. I. F. Atividade respiratória e evolução de etileno em alface crespa minimamente processada armazenada sob duas temperaturas. Ciência e Agrotecnologia, Lavras, v. 32, n. 6, p. 1985-1990, 2008.

MORAES, I.V.M. Dossiê técnico, conservação de hortaliças. 2006. Disponível em: <http://www.
respostatecnica.org.br/dossie-tecnico/downloadsDT/ $\mathrm{MzE}=>$. Acesso em: 07 fev. 2017.

PORTE, A.; MAIA, L.H. Alterações fisiológicas, bioquímicas e microbiológicas de alimentos minimamente processados. Boletim do Centro de Pesquisa de Processamento de Alimentos, v. 19, n. 1, 2001.

SIDONIO, M. Fatores intrínsecos e extrínsecos. 2012. Disponível em: http://nutrimico.blogspot.com. br/2012/10/fatores-1.html. Acesso em: 15 de maio 2017.

TUDELA, J. A.; MARÍN, A.; MANRTíNEZ-SÁNCHEZ, A.; LUNA, M. C.; GIL, M. I. Preharvest and postharvest factors related to off-odours of fresh-cut iceberg lettuce. Postharvest Biology and Technology, v. 86, p. 463-471, 2013.

Recebido em: 13 de fevereiro de 2017 Aceito em: 23 de maio de 2017 